\title{
Framing innovation practices in interstitial issue fields: Open innovation in the NYC administration
}

\author{
Maximilian Heimstädt \\ Witten/Herdecke University \\ Reinhard Mohn Institute of Management \\ Alfred-Herrhausen-Strasse 50 \\ 58448 Witten, Germany \\ maximilian.heimstaedt@uni-wh.de
}

\author{
Georg Reischauer \\ WU Vienna University of Economics and Business \\ Department of Strategy and Innovation \\ Welthandelsplatz 1 \\ 1020 Vienna, Austria \\ georg.reischauer@wu.ac.at
}

Cite as:

Heimstädt, M., \& Reischauer, G. (2019). Framing innovation practices in interstitial issue fields: Open innovation in the NYC administration. Innovation: Organization \& Management, 21(1), 128-150. 


\title{
Framing innovation practices in interstitial issue fields: Open innovation in the NYC administration
}

\begin{abstract}
Public sector organizations increasingly innovate through open innovation practices that originated in the private sector. To explain the use of these innovation practices, extant research has focused on enabling conditions at the individual and organizational level, but has paid little attention to extra-organizational factors such as culture. To address this gap, we adopted a field framing perspective to study the use of open innovation practices in the New York City (NYC) administration. We found that actors in NYC equipped different social positions - insider, outsider, and interstitial - and used different discursive tactics - reflective frame blending and supplemental frame blending - to enhance the cultural resonance of open innovation practices. We further theorize these findings with a framework on the enabling conditions for the cultural resonance of innovation practices. Our study contributes to innovation studies by unpacking the role of culture for the use of innovation practices and to the framing literature by specifying the role of discursive tactics and social positions for the cultural resonance of new practices.
\end{abstract}

Keywords: framing; frames; issue field; discourse; culture; organizational practice; open innovation; public sector innovation 


\section{Introduction}

Innovation in public sector organizations is most often performed through a practice called the "policy cycle" whereby a political mandate instructs agencies to set up a request for proposals, decide on a contractor, and manage the implementation of a new service or process (Mergel \& Desouza, 2013). Over the last years, stakeholders began to raise concerns that this innovation practice is increasingly unable to meet the demands for contemporary public innovation as government agencies face more turbulent and heterogeneous environments (Bogers, Chesbrough, \& Moedas, 2018). As a potential solution, scholars point towards more transparent and participatory innovation practices subsumed under the label "open innovation" that have already been used in the private sector (Chesbrough, 2003; West \& Bogers, 2017; Heimstädt \& Reischauer, 2018). Examining pioneer projects of open innovation in the public sector, an emerging body of literature has found positive effects, including improved awareness of social problems, improved services based on broad citizen experience, and increased trust in government (Bogers et al. 2018; Cohen, Almirall, \& Chesbrough, 2016; Mergel \& Desouza, 2013). Still, the policy cycle remains the dominant innovation practice in the public sector (Kankanhalli, Zuiderwijk, \& Tayi, 2017). To understand enabling conditions and barriers for using open innovation practices, scholars have so far studied mainly individual factors such as mindset or organizational factors such as innovation culture (Kankanhalli, Zuiderwijk, \& Tayi, 2017). To date, only few studies have directed their attention to extra-organizational and societal factors including the role of language and shared understanding of what makes an appropriate innovation practice (Mergel, 2018).

With our study, we seek to address this gap by taking a field framing perspective. Field frames are "jointly constructed cultural templates" (Cornelissen \& Werner, 2014, p. 185) that are shared across a field and that result from the interaction of organizations in this field. Field frames bracket organizational attention and create a status ordering of practices that are deemed more appropriate than others (Lounsbury, Ventresca, \& Hirsch, 2003). Frames vary with respect to the cultural resonance, i.e. the degree to which they convince and mobilize actors to act according to the articulate frame (Werner \& Cornelissen, 2014, p. 1461). In our case this refers to the use of open innovation practices in the public sector. The field in which framing activities around public open innovation practices take place is best described as an "interstitial issue field" (Zietsma et al., 2017). Such a field is characterized by great heterogeneity of actors, some of whom are embedded into more than one field (Zietsma et al., 2017). To examine framing in interstitial issue fields in a systematic manner, extant theory suggests to study the 
effects of two key factors, discursive tactics that actors use (Werner \& Cornelissen, 2014) and the social positions of actors in an issue field (Furnari, 2014, 2017). Against this background, we set out to answer the following research question: How do discursive tactics and social positions of actors affect the cultural resonance of innovation practices in interstitial issue fields?

We addressed this question with a longitudinal single-case study on the introduction of open innovation practices to the administration of New York City (NYC). Based on over 100 document pages, 26 interviews and more than 50 days of participant observation, we identified three open innovation practices with a strong cultural resonance: innovating through the public competition BigApps, innovating through the inter-agency-hub MODA, and innovating through exchange with the volunteer community BetaNYC. Actors increasingly used these innovation practices next to the proven innovation practice of the policy cycle. To establish such cultural resonance in the interstitial issue field of the NYC administration, we found that actors equipped different social positions in the field - insider, outsider, and interstitial - and employed reflective and supplemental frame blending as different discursive tactics. In an iterative process of abductive reasoning (Mantere \& Ketokivi, 2013), we theorized these findings with a framework on the enabling conditions for the cultural resonance of innovation practices. This framework contains three groups of combinations of discursive tactics and social positions that are stratified by their likelihood of increasing the cultural resonance of innovation practices. With these findings, we add to research on public sector innovation, studies of the cultural constitution of innovation, and the framing literature.

\section{Theoretical Background}

\section{Open Innovation Practices in the Public Sector}

Organizational practices are shared routines that organizations mobilize in their day-to-day work (Ansari, Fiss, \& Zajac, 2010). Practices that recently receive growing attention by organization scholars and practitioners alike are those that public sector organizations use to innovate (Arundel et al., 2015; Demircioglu \& Audretsch, 2017; Potts \& Kastelle, 2010). In most public sector organizations today, the predominant innovation practice is the "policy cycle", in which a political mandate instructs agencies to innovate a public service, and in which agencies eventually set up a request for proposals, select a contractor, negotiate a contract and manage the implementation (Arundel et al., 2015; Mergel \& Desouza, 2013). Over the last years, stakeholders outside and inside the public sector have increasingly articulated 
concerns that this innovation practice is unable to meet the needs of citizens, especially in large cities with a rapidly changing and highly heterogeneous population (Bogers, Chesbrough, \& Moedas, 2018; Heimstädt \& Reischauer, 2018).

As a pathway towards services that better meet citizens' needs, critics of the established policy cycle practice point towards more open forms of public sector innovation (Goldstein \& Dynson, 2013; Lathrop \& Ruma, 2010)1 ${ }^{1}$ The term "open innovation" emerged in the private sector and refers to a wide array of practices through which organizations purposely manage inflows and outflows of knowledge to accelerate internal innovation and to expand markets for the external use of innovation (Chesbrough, 2003; West \& Bogers, 2017). One example of a widely used open innovation practice is the sourcing of ideas and content from a larger audience, the "crowd" (Dobusch \& Kapeller, forthcoming). To date, scholars and practitioners alike have provided substantive evidence that more open forms of innovation in private sector firms can increase the fit between product or service and market (West \& Bogers, 2017).

Inspired by these findings, scholars began to explore the applicability and effects of open innovation practices for the public sector (Hilgers \& Ihl, 2010; Seltzer \& Mahmoudi, 2012; Kankanhalli et al., 2017). Public open innovation practices differ from participatory elements in traditional policy cycle practices as they go beyond the involvement of professional service providers and localized communities directly affected by a policy. Rather, public open innovation practices follow the principle of global search (Dobusch \& Kapeller, forthcoming) and aim at mostly nonprofessional problem solvers who are usually not part of the participation processes (Mergel, 2018). Among the positive effects of public open innovation practices are improved awareness of social problems, improved services based on broad citizen experience, more cost-efficient provision of services, and increased trust in government (Bogers, et al., 2018; Cohen, et al., 2016; Mergel \& Desouza, 2013). However, despite these positive effects of open practices, innovation in the public sector to date remains dominated by the more closed policy cycle practices (Kankanhalli et al, 2017). This raises questions regarding the enabling conditions of open innovation practices in the public sector. Previous studies along this line of inquiry have found that public agencies lack funding for open innovation projects or an innovation culture that is sufficiently open for experimentation and creativity (Bekkers et al., 2013). Several of these studies focus on intra-organizational dynamics or on the dynamics

\footnotetext{
${ }^{1}$ Some authors refer to "open government" when describing practices of public open innovation. We understand open government as a much broader "umbrella concept" (Hirsch \& Levin, 1999) which includes but goes beyond practices of open innovation. In this study, we therefore refer consistently to public open innovation practices, even if some of the studies we cite use the term open government.
} 
between agencies and policy makers to explain change or stability in practices of public sector innovation (Felin \& Zenger, 2014; Murray, Stern, Campbell, \&. MacCormack. 2012). One of the few studies that build on these insights but also widens the focus towards broader "extraorganizational and societal factors" is Mergel's (2018, p. 730) analysis of the open innovation platform Challenge.gov in the United States. Speaking to public managers who included the new platform in their innovation practice, she finds that these open innovation pioneers previously perceived a "cultural shift" (Mergel, 2018, p. 735) towards more open forms of innovating. These insights indicate that besides individual, organizational and political-legal factors (e.g. regarding the design of political mandates for open innovation), broader cultural concepts like values, norms and language play an influential role as enabling conditions of open innovation practices in the public sector. Capturing the influence of these broader cultural concepts requires a theoretical lens that pays attention to the cultural embeddedness of public sector organizations. The field framing perspective presents such a lens.

\section{Field Framing Perspective}

The question of how new organizational practices enter a field and become accepted is a longstanding and multifaceted one (Ansari, Fiss, \& Zajac, 2010). A strand of research within the broad tent of organizational scholars interested in culture (Giorgi et al., 2015; Weber \& Dacin, 2011) that resonates well with Mergel's (2018, p. 735) observation of a "cultural shift" in public sector innovation centers around discourses and frames that practices are embedded in and that actors draw upon). Discourse refers to the communicative action between organizations by which their social reality is formed and reproduced (Maguire, Hardy, Lawrence, 2004; Meyer \& Höllerer, 2010; Phillips, Lawrence, \& Hardy, 2004). Discourses are also key to understand why some organizations are more willing to use innovation practices than others (Reischauer, 2018). Through the lens of discourse, a change of public sector innovation from closed (as in the policy cycle) to open could hence be understood along the discursive processes in which organizations calibrate their shared understanding of appropriate innovation practices.

A widely-used approach to study discourses is through the concept of frames (Cornelissen \& Werner, 2014). Grounded in Goffman's (1974) work, frames are schemas for doing and saying that bracket attention and thereby define what is important and appropriate, or not, for an individual or an organization (Giorgi, Lockwood, \& Glynn, 2015). They differ with respect to their cultural resonance, i.e. with respect to degree to which they are "effective in appealing to others and to mobilize them into action" (Werner \& Cornelissen, 2014, p. 1461). 
A high cultural resonance makes the use of new practices more likely (Werner \& Cornelissen, 2014). Studies on frames have generated important insights on the relationships between culture and innovation. Using the labels "technological frames" and "innovation narratives", scholars examined how the framing of a new technology within a single organization varies across users and is responsible for differences in how this technology is implemented and used (Bartel \& Garud, 2009; Cornelissen \& Werner, 2014). Another line of research examined how frames shape an organization's overall approach to innovation. It was found that if an organization frames innovation as an opportunity, the development of innovative projects is more likely (Salomo et al., 2008). In a similar vein, framing an innovation as either an opportunity or a threat can be crucial to foster or inhibit inter-organizational knowledge transfer in innovation projects (van Burg, Berends, \& van Raaij, 2014).

As these studies showcase, a focus on frames helps to better understand how organizations innovate. But frames shape innovation also on levels beyond the organizational one. In their review of the framing literature, Cornelissen and Werner (2014) differentiate between micro-level, meso-level and macro-level frames. Most suitable for our interest in a broader cultural shift towards open innovation practices in the public sector is the macro-level concept of field frames. Field frames are "jointly constructed cultural templates" (Cornelissen \& Werner, 2014, p. 185) and result from the interaction amongst organizations of a field. According to Lounsbury and colleagues, field frames lend order and meaning to a field of activity "by creating a status ordering for practices that deem[s] some practices as more appropriate than others" (2003, p. 77). To understand why certain practices become considered appropriate and have a high cultural resonance while others do not, studying discursive actions between actors that affect field frames linked to the practice in question is a major factor. For this purpose, Werner and Cornelissen's (2014) typology on discursive tactics provides important insights. The authors distinguish between the two different tactics they label "frame shifting" and "frame blending". Frame shifting refers to discursive tactics whereby actors challenge the status quo and promote an alternative frame that is distinctly different from the prior cognitive template. These tactics oftentimes involve forms of disjunctive and counterfactual language. Frame blending refers to discursive tactics whereby actors skillfully iterate between, or dialectically integrate existing cognitive templates in a field in order to eventually establish a novel template. These tactics oftentimes involve conjunctive language and analogies. 
Besides discursive tactics, framing scholars agree that another major factor influencing the cultural resonance of practices is the social position of an actor in a field. An actor's social position shapes the likelihood that a discursive tactic will find resonance with relevant field participants (Furnari, 2014, 2017; Maguire, et al. 2004). For example, in centralized fields only few actors with central social positions exert dominance over other actors. In such fields, issues with which actors at central social positions are blamed are likely to trigger changes in that field as contestation mobilizes non-central actors (Furnari, 2017). Which social positions actors can equip in a field depends on the type of field. Among the growing numbers of field types described in the organization and management literature (Zietsma et al., 2017), the one that resonates best with our interest in public open innovation is the issue field (Hoffman, 1999; Meyer \& Höllerer, 2010). The notion of an issue field was developed in contrast to field concepts that saw a technology or a product as the connecting element of all field members. An issue field brings together actors with various purposes around a discursive issue (Hoffmann, 1999). Recently, a finer-grained typology of different issue fields has been developed, including the "interstitial issue field" (Zietsma et al., 2017, p. 401-2). Interstitial issue fields are characterized by actors who equip a social position in more than one issue field (De Vaan, Stark, \& Vedres, 2015; Vedres \& Stark, 2010). These "multiply embedded actors" (Zietsma et al., 2017, p. 407) are embedded in the discourse of one field, but at the same time draw from and contribute to discourses in other fields.

Against the backdrop of this important research, we identify three limits regarding innovation practices that require greater attention. First, while a growing number of studies focuses on the role of social position in innovation practices (Furnari, 2014; De Vaan, Stark, \& Vedres, 2015; Vedres, \& Stark, 2010), little attention has been paid to the role of social positions for the field-wide framing of innovation practices. Second, while previous research has studied discursive tactics and social positions separately, we know little about how their combinations affect framing (Werner \& Cornelissen, 2014). Third, and relating back to research on open innovation in the public sector more broadly, extant research has so far hardly examined the role of field-level discourse to better understand why public sector organizations use open innovation practices (Bekkers et al., 2013; Mergel, 2018; Mergel \& Desouza, 2013). To address these limitations, we seek to understand how the discursive tactics and social positions of actors affect the cultural resonance of innovation practices in interstitial issue fields. 


\section{Methods}

\section{Research Design and Case Selection}

To address this research interest, we opted for a longitudinal single-case study research design (Eisenhardt, 1989). We define a case as an issue field that consists of all public agencies of a large city and all organizational and individual actors that engage in the issue of public sector innovation in that city. Fields with discourses on public sector innovation serve as excellent examples of interstitial issue fields (Zietsma et al., 2017) as they are characterized by a group of focal actors (city agencies) and a highly heterogeneous group of actors that are embedded in other fields as well (e.g. business, community, science). In the practitioner-oriented (Leber, 2016) and academic literature (Sang, Taewon, \& Donghyun, 2012), the city administration of NYC has been portrayed as a pioneer with respect to open innovation practices. NYC therefore presents a "revelatory case" (Yin, 2013, p. 67) that allows us to study multiple facets of the cultural resonance of innovation practices.

\section{Data Collection}

The first author collected data between July and October 2015. The aim of the data collection was twofold. First, we wanted to learn about the variety of open innovation practices in NYC and engage with the public managers who use them. Second, we wanted to understand which actors shaped the discourse on public sector innovation in NYC. To meet these objectives, the first author collected three types of data (see Table 1 for a summary).

\section{\#\#\# Table 1 about here \#\#\#}

(1) Documents. In the field entry phase, the first author collected documentary data with a deliberately wide scope, as this allowed him to learn about different open innovation practices and the actors involved in the discourse on public sector innovation. These documents included media reports (e.g. New York Times, Politico, TechPresident), videos (e.g. public hearings or conferences), blog posts and tweets (e.g. by city agencies or individual civil servants), policy documents (e.g. mayoral reports), as well as legal and administrative documents (e.g. bills, laws, minutes).

(2) Interviews. The first author further conducted 26 semi-structured interviews with different types of actors in NYC. On the one hand, the author conducted interviews with focal actors from the public sector, respectively city agencies (5 interviews) and the city council (3 interviews). These actors were either directly or indirectly associated with open innovation practices (e.g. by performing or advocating them). On the other hand, he interviewed actors 
who engaged in discursive tactics regarding public sector innovation in NYC but who were not members of the city administration. This included members of civic technology volunteer groups (9 interviews), advocacy organizations (4 interviews), technology firms (3 interviews), and research institutes (2 interviews).

(3) Observations. To study the "cultural shift" (Mergel, 2018, p. 735) towards open innovation in its day-to-day production, the first author further engaged in participant observations. For a period of 51 days he joined the NYC-based volunteer group "BetaNYC" that experiments with and advocates for the use of digital technologies in the NYC administration. The author helped organize weekly community meetings at different coworking spaces ("hack nights"), and accompanied volunteers and community organizers to meetings with other actors of NYC's local government field (e.g. at university facilities, startup offices, or city agencies). In total, the first author participated in 20 events, during which discursive interactions between actors regarding public innovation in NYC could be observed first-hand.

\section{Data Analysis}

Our data analysis involved three steps. In the first step we engaged deeply with the outcome that we wished to explain: new and more open practices by which public sector organizations in NYC innovate. We integrated all documents, interviews, and observations in the software MAXQDA and started coding for open innovation practices (Corbin \& Strauss, 1990). Across the more than 50 city agencies in NYC, we found a wide array of practices. To strike a balance between evidence for a broader shift towards open innovation and in-depth descriptions of the culture of openness inscribed in these practices, we subsequently narrowed down our inquiry to three practices for which we asserted a strong cultural resonance: innovating through the public competition BigApps, innovating through the inter-agency-hub MODA, and innovating through exchange with the volunteer community BetaNYC. We developed timelines on the emergence of these practices, including key events and publications on how these open innovation practices were framed. This process bracketed our analysis to a period of 13 years, ranging from the inauguration of Michael Bloomberg as Mayor of NYC in 2002 to the end of data collection in late 2015. Table 2 provides an overview of selected key events of the observation phase.

\section{\#\#\# Table 2 about here \#\#}

In the second step of our analysis we focused on the identification of discursive tactics and social positions. We went back to our data and engaged in open coding (Corbin \& Strauss, 
1990). Against our initial assumption that the heterogeneity of interstitial issue fields leads to a broad variety of frames, we found that most frames circulated around terms such as flexibility, modernity or collaboration. At the same time however, we became aware of two more interesting patterns in our codes, which we followed up through axial coding (Corbin \& Strauss, 1990). First, we found that a wide array of actors was involved in the discourse on public sector innovation in NYC. Our codes included types such as "journalist", "tech pundit", "consultant", "civil rights advocate", "civic hacker", "mid-tier city employee", "upper-tier city employee", or "local politician". Venturing back and forth between our codes and the literature on organizational fields (Zietsma et al., 2017) allowed us to sort the first-order codes into a second-order typology of social positions: "insider", "outsider", and "interstitial". Second, we found a broad spectrum of rhetorical means and discursive tactics that actors used to present their frame. Our codes included tactics such as "calling out a deficit", "drawing a comparison to other local governments", "drawing a comparison to other sectors", "demanding reinforcement", or "reflecting on tradition". Moving back and forth between our codes and the literature on discursive tactics (Werner \& Cornelissen, 2014), we found that our first-order codes regarding discursive tactics resonate best with the concept of "frame blending", a "type of analogical reasoning [that] involves associating words and schemas, and constructing correspondences between them" (Werner \& Cornelissen, 2014, 1458). Moreover, we discovered that actors used different variants of frame blending that varied with respect to the origins of words and schemas that they associated with one another to blend the innovation frame. We labeled these variants "reflective frame blending" and "supplemental frame blending".

In the third and final step of our analysis, we engaged in theory building from case study data (Eisenhardt, 1989). For this purpose, we brought together the three social positions (insiders, outsiders, interstitials) with the two variants of frame blending (reflective frame blending, supplemental frame blending) and carefully linked discursive episodes in which the six respective combinations occurred (e.g. "outsider/reflective frame blending") with the use of open innovation practices. One exemplary method of establishing these links was when city managers who engaged in open innovation mentioned frames and rhetorical figures, which we had coded for in the previous step of the analysis. This process was challenging, highly iterative, and informed by an abductive approach in which we theorized links between these combinations and cultural resonance when they "account[ed] for the observations in light of the rule" (Mantere \& Ketokivi, 2013, p. 71). The outcome of this step was a theoretical framework 
on the enabling conditions for the cultural resonance of innovation practices (Figure 1, presented at the end of the findings section).

\section{Findings}

We first outline three open innovation practices for which we observed a particularly strong cultural resonance in the NYC interstitial issue field. We then describe and illustrate the social positions that actors held and the dominant discursive tactics they used to enable this change. In the final step, we theorize these findings with a framework on the enabling conditions for the cultural resonance of innovation practices.

\section{Open Innovation Practices in NYC}

The introduction of open innovation practices in the NYC administration is interwoven with the reign of the entrepreneur and self-made billionaire Michael Bloomberg who was inaugurated as 108th Mayor of NYC in January 2002. In his electoral campaign, Bloomberg positioned himself as a political newcomer and pragmatic leader, able to navigate the city administration through looming "threats of terrorism and economic turmoil" (New York Times, November 7, 2001). Bloomberg's first period as Mayor was dominated by the post- $9 / 11$ reconstruction of lower Manhattan and efforts to improve responsiveness to terrorist threats, e.g. by bringing in an external management consulting firm to scrutinize the crisis response routines of the Fire and Police Departments. Another project of this period, which signaled the government's interest in greater openness of the administration, was the establishment of the non-emergency hotline 311 , as a central hub for citizens who seek information from or want to make suggestions to any city agency. In 2005, Bloomberg successfully ran for a second period as Mayor of NYC, which eventually became dominated by the financial crisis of 2007 and 2008. After a third term, Bill de Blasio took over as Mayor in 2014, continuing many of the innovation projects initiated by Bloomberg. Between 2002 and 2015 (the end of data collection), the discourse on public sector innovation in NYC had broadened substantially to include not only the established policy cycle practice but also open innovation practices were increasingly framed as beneficial. The new practices include innovating through the public competition BigApps, innovating through the inter-agency-hub MODA, and innovating through exchange with the volunteer community BetaNYC. In the following, we describe these practices and how they differ from the policy cycle practice.

In October 2009, one month before Bloomberg's third mayoral election, the city government launched the app development competition BigApps together with a web portal 
offering over 170 openly licensed data sets from different city agencies (e.g. traffic updates, event schedules, property sales, restaurant inspections, data on school and voting districts). Targeted at "designers, developers, academics, entrepreneurs, and New Yorkers at large", the organizers described BigApps as a "civic innovation competition". Based on the data sets and a set of broadly defined "urban challenges" to address, participants were asked to submit prototypes of their "civic apps". A multi-sector jury assessed the prototypes and potentially awarded seed funding, access to marketing channels, and further training for the team (NYC BigApps, 2009). After the first round in 2009, the competition was repeated annually until 2015, the year of data collection, in which more than 100 teams submitted their innovation projects. Compared to the traditional innovation practice of the policy cycle, Big Apps represented a more open practice of public sector innovation as the search for innovative ways to use city data was opened up, from single city agencies to external project teams.

Only a few weeks into his third term, Bloomberg issued an executive order to establish the Mayor's Office for Data Analytics (MODA). The purpose of MODA was to address public service problems of greater complexity than those that can be addressed through public competitions like BigApps. MODA did so by identifying problems that required cross-agency collaboration, reaching out to the relevant agencies, and combining information and resources from multiple city agencies to develop predictive models. These "information products" (as employees referred to these models in the interviews) were then fed back into one or more city agencies, enabling them to better address pressing issues (interview with MODA employee). One of the first services developed by MODA, an algorithm to improve the allocation of the Fire Department's resources, helped to raise the rate of inspections that identify severe violations of fire regulations from $21 \%$ to $71 \%$. By the end of 2013, MODA had four ongoing and twelve scheduled cross-agency innovation projects (MODA Annual Report, 2013). Compared to the policy cycle, MODA represented a more open practice for public sector innovation, as urban problems were addressed through networked collaboration, spanning the boundaries of single city agencies.

In summer 2008, a group of citizens interested in the use of digital technology in local government formed through online forums and mailing lists and established the "civic technology" volunteer group BetaNYC. At their regular offline meetings ("hacknights"), around 15 to 25 participants discussed urban problems (e.g. public transport quality, homelessness, or street safety) and worked on innovative ways to address them (e.g. through apps, plugins, or digital campaigning tools). Reluctant at first, over the years more and more city employees 
participated at the hacknights. Oftentimes, they brought with them a short presentation of an ongoing innovation challenge they were facing in their agency, and asked for ideas, feedback, and support. During his time as a volunteer at BetaNYC, the first author, for example, observed collaboration between agencies and community on the optimization of bus schedules or the draft of a technology bill to be submitted to City Council. Compared to the policy cycle, exchange with the volunteer community presented a more open practice of public sector innovation, as city agencies partially moved the idea generation and feedback phases of their innovation process into the group of "civic hackers".

\section{Social Positions in NYC: Outsiders, Insiders, and Interstitials}

Since the early 2000s, more and more actors participated in the discourse on public innovation in NYC. We identified that these actors assumed three distinct social positions that vary regarding their relation to public innovation practices and regarding their embeddedness in other fields: outsiders, insiders, and interstitials.

Outsiders are actors who attempt to change frames regarding innovation practices used by organizations in the issue field, yet are not members of these organizations. They are embedded in one or more other issue fields. In NYC, outsiders were actors who engaged in the discourse on public sector innovation from a position outside the city administration. An example of outsiders in NYC were journalists who focused on the nexus of government and technology. In 1999, a local government watchdog organization founded the web magazine Gotham Gazette, reporting on policy development and tracking policy implementation. Between 2004 and 2015, the NYC-based website TechPresident provided national coverage on the use of web-technology in political campaigns and government. In 2015, the editorial team of TechPresident transitioned to the newly founded blog Civicist and developed an even stronger topical focus on the use of technology in public sector innovation. Through sponsorships and op-eds, these "govtech media outlets" (interview) maintained close relationships with another type of outsiders: employees of large technology companies. With job titles such as "Director of Civic Technology" or "Technology Evangelist", these employees either engaged directly in public debates on the use of technology in government (e.g. through blog posts or participation in conferences and meetups), or provided resources, e.g. office space, in which public debates on public innovation could take place.

Insiders are actors who attempt to change frames regarding innovation practices used by organizations in the issue field of which they are a member of. They are hardly embedded in other issue fields. In NYC, insiders were members of city agencies or other government 
organizations, who - beyond their day-to-day work context - engaged in the framing of how public sector innovation should be performed. Insiders not only framed public innovation in their city agency, but they also addressed the field discourse through Twitter, personal blogs, and through the mailing lists maintained by the civic hacking community. Our analysis revealed that besides local politicians and their personal teams, some insiders were senior city employees who have been working in technology-related roles, e.g. on communication infrastructure, databases, or websites. Other insiders were actors in more junior positions in the city administration. Their motivation to advocate an open approach to public sector innovation was shaped through their recent education in which they were exposed to tools and theories that relate the use of web-technology to the reinforcement of democratic institutions. One of our interview partners, a junior urban planner who joined the city administration straight after college, reported how after joining the department he began to "advocate internally" for his belief that agency information should be shared more widely and across the organizational boundary to improve existing public services:

"I thought that the number of things you could do with the data was limitless. A reason to make it more open, right? Because what we can do in our small office with our resources is so limited compared to what... If you free that data and give it to anybody, what they can do. [...] In the long run, I think, it helps improve democracy [...].”

Interstitials are actors who attempt to change frames regarding innovation practices used by organizations in the issue field of which they are a member of. In contrast to insiders however, they are embedded in one or more other issue fields as well, e.g. because of their former employment and/or as strong personal brand. In NYC, interstitials were actors who held a position in the city administration and who leveraged their former role in business or technology entrepreneurship when addressing the field with their vision of public innovation. As outlined in the previous section, the rise of open innovation in the NYC administration was inextricably linked to Michael Bloomberg, Mayor of NYC from 2002 to 2014. However, the effect he had for the use of open innovation practices cannot be explained by his position as Mayor of NYC alone. Consider the example of Bloomberg's predecessor Rudy Giuliani who failed to establish New Public Management as dominant paradigm for the NYC administration (Weikart, 2001). When addressing the issue of public innovation as Mayor of NYC, Bloomberg persistently created references to his former role as technology entrepreneur and self-made billionaire. As a result, press releases and media reports on public sector innovation in NYC oftentimes referred to him as a "results-based" businessman, who applies a "corporate 
executive's by-the-numbers approach" (New York Times, October 18, 2005) to implement his "data-driven policies" (interview with city employee).

However, not only the omnipresent Mayor Bloomberg but also other members of the NYC administration leveraged their former roles as outsiders when engaging with the field frame of public innovation. Mike Flowers, head of MODA and first "Director of Analytics" in NYC, regularly linked his advocacy for more successful innovation through inter-agency knowledge collaboration to his previous experiences in Iraq. Being involved in the logistics around the trial of Saddam Hussein, Flowers explained how he witnessed firsthand the benefits of greater openness when "intelligence analysts would combine field reports with details about the location, time, and casualties of past IED [improvised explosive device] attacks to predict the safest route for that day" (Slate Magazine, March 6, 2013).

Another telling example for an interstitial actor is Rachel Sterne, NYC's first "Chief Digital Officer" (CDO) who was appointed in 2011. In the three years in which she held this role, she toured conferences and media outlets to present her vision of more open public innovation practices in NYC. Over and over, she articulated that city agencies should take the role of a "platform" on which third parties could develop "solutions" (in the sense of ITsolutions) to urban challenges (Strata Conference, September 22, 2011). When appointed as $\mathrm{CDO}$, the by then 27-year-old Sterne had no prior experience in government, yet had already founded a citizen journalism startup, set up a digital strategy consulting firm, and, as an adjunct professor, taught a seminar on social media and entrepreneurship at Columbia Business School. In several press articles, she was portrayed as a local government employee who at the same time embodied "everything that is happening in the technology industry" (WNYC, January 25, 2011).

\section{Discursive Tactics in NYC: Reflective and Supplemental Frame Blending}

Actors in all three social positions tried to enhance the cultural resonance of innovation practices in NYC. What they further had in common was that none of them tried to radically change the cultural resonance of the existing innovation practice, i.e. the innovation policy cycle. However, while all actors tried to broaden the existing field frame, they employed two distinctly different variants of frame blending. These variants differed with respect to the origins of words and schemas that they associated with one another to modify the innovation frame. Additional data on both tactics can be found in Table 3 . 
When engaging in reflective frame blending, actors blend the innovation frame by recombining and revisiting words and schemas that are already part of the current field discourse. In NYC, actors who engaged in reflective frame blending argued that openness as an organizing principle with the potential to improve innovation around public services had always been a principle of NYC's public administration and that the competencies (e.g. conversing with citizens) and resources (e.g. IT infrastructure) needed to make openness more salient already existed within city agencies.

In 2014, a key member of the civic technology volunteer group BetaNYC was invited to give a speech at Personal Democracy Forum, the same conference that Mayor Bloomberg had used to announce the first BigApps competition five years before. This member articulated that city agencies should embrace collaborations with the community of civic hackers to create better public services. Reflecting upon the time when he moved from the countryside to NYC, the volunteer technologist told the audience that "among the first things [he] learned about the city was that Central Park was designed by a bunch of amateurs" and that "the base of the Statue of Liberty was made possible through a crowdfunding campaign" (Personal Democracy Forum, June $5^{\text {th }}$, 2014). By bringing in these historical anecdotes, he framed open innovation as something rooted in longstanding city values and hence appropriate to also be used by city employees. However, the civic hacker's reflective frame blending - from the social position of an outsider - found only very limited resonance with city employees and other field actors, as it was neither picked up by any media coverage, nor mentioned or referred to in any of our interviews with city employees. When speaking to city employees who pitched their innovation problems during the BetaNYC hacknights, civic hackers instead justified their appearance with rhetorical figures promoted by other actors in the field (e.g. the one presented in the following section).

When engaging in supplemental frame blending, actors blend the innovation frame by bringing in and leveraging words and schemas that have not yet been part of the current field discourse. In NYC, actors who engaged in supplemental frame blending argued that openness as an organizing principle to improve the effectiveness of public innovation needed to be imported from other fields to serve as a supplement to existing capabilities of the public sector. The competencies and resources necessary to realize openness, they argued or at least implied, were to be found in other domains of innovation, such as technology entrepreneurship or corporate business. 
Between 2011 and 2014, NYC's CDO Rachel Sterne toured conferences and media outlets to promote her belief in the city government as a "platform" which - like Facebook or Google - would invite outsiders to develop services on top of its infrastructure. At a large conference for technology professionals in NYC, Sterne iterated the metaphor of "city as a platform" and argued that this alternative form of doing public innovation "empowers citizens to collaboratively solve problems". After referring multiple times to the technological competencies of her audience (a mix of city employees and other participants), she directly addressed them and argued that "as a city we need your help!" (Strata Conference, September 22, 2011). Through the platform metaphor, Sterne stressed the different yet still important role of the state in her vision of public innovation. However, at the same time, her metaphor suggests that for its realization, city agencies need to draw on competencies and resources from other fields. Sterne's supplemental frame blending - from the social position of an interstitial found substantive resonance within and beyond the interstitial issue field of NYC. Her frame was not just picked up by high-impact media outlets such as TechCrunch, Huffington Post or Vogue. Also public agencies such as the National Aeronautics and Space Administration (NASA) also blogged about Sterne's ideas with which they "couldn't agree more" (Open.NASA.gov, July 28, 2011). Through Twitter, Sterne and her audience amplified her public appearances across and beyond the local government field, stimulating widespread approval from non-government employees ("Loving what@ @rachelhaot is saying about open government engagement"; @jonbaltz, July 11, 2013) and from government employees ("Sharing \#opendata with the public helps foster better internal sharing of data - @ rachelhaot Totally agree!"; @mheadd, June 6, 2013)².

\section{Enabling Conditions for the Cultural Resonance of Innovation Practices}

Building on this analysis, we develop a theoretical framework on the enabling conditions for the cultural resonance of innovation practices (Figure 1). The framework consists of the six possible combinations between the three social positions of actors (outsider, insider, interstitial) and the two discursive tactics (reflective frame blending, supplemental frame blending). An exemplary combination is "outsider position/ supplemental frame blending". The framework sorts the six combinations into three groups, stratified by the likelihood (low, medium, high) that a combination of social positon and discursive tactic will positively affect the cultural resonance of innovation practices. We thereby make no deterministic arguments, depriving

\footnotetext{
${ }^{2}$ By the time of data collection Sterne had changed her Twitter-handle to @ rachelhaot.
} 
some actors from the ability to affect change, yet provide a map to better understand distributed contributions to the collective effort of frame change.

\section{\#\#\# Figure 1 about here \#\#\#}

The first group covers combinations of social positions and discursive tactics for which we theorize a low likelihood of enhancing the cultural resonance of an innovation practice in an issue field. In this group, we find outsiders who engage in reflective frame blending and insiders who pursue supplemental frame blending. In both combinations, a mismatch between social position and discursive tactic leads to modest resonance with focal actors in the field. An example of this group in NYC is the aforementioned civic hacker (outsider) who linked his propositions for greater collaboration between city agencies and volunteer community with the city's longstanding values of openness (reflective frame blending). Another example from is a senior city employee (insider) who framed openness as something that the NYC administration should learn from public agencies in Washington D.C. (supplemental frame blending). For this framing activity we however found no noticeable resonance with focal actors in NYC (Table $3)$.

The second group comprises of all those combinations for which we theorize a medium likelihood of enhancing the cultural resonance of an innovation practice in an issue field. In this group, we find outsiders who engage in supplemental frame blending, as well as insiders and interstitials who engage in reflective frame blending. In all three combinations, noticeable frame resonance with focal actors is explained by a match between social position and discursive tactic. Exemplary for this group in NYC are corporate evangelists (outsider) who advocated for greater inclusion of external communities and entrepreneurs in the innovation process in public agencies (supplemental frame blending). We found different forms of resonance. Some city employees and politicians responded critical to technology evangelists and called for "no vendor policies" in debates about public innovation (interview with technology evangelist). Others responded positively and perceived a fit with their problem situation. As a local politician put it: "I see this public transport problem [...] and I can send my policy director to the hacknight at [a corporate office] and he gets help on that problem" (personal interview). Another example for this group is Mayor Michael Bloomberg (interstitial) who argued that government data sets belong to citizens already and that the only hurdle to public innovation is their creativity and willingness to use the data (reflective frame blending). Again, the resonance of this framing activity with members of the city administration was mixed. While many city employees and politicians publicly affirmed this frame (e.g. on 
Twitter), the first author engaged in informal conversations with city employees in which Bloomberg's framing around BigApps was criticized for underestimating the challenged of sharing government data sets with the public. A further example that emerged from our data is that of a high-ranking city manager (insider) who in press releases and media portraits repeatedly stressed that city agencies face no risk but plenty of advantages when opening up towards citizens (reflective frame blending, see additional data in Table 3). While some many city employees were critical at first, the city manager perceived that "people in city agencies became more open [i.e. releasing more data]" once further actors in NYC engaged in framing activities, too.

The third group encompasses one combination for which we theorize a high likelihood of enhancing the cultural resonance of an innovation practice in an issue field. At first sight, the social position of the interstitial actor as a member of a focal organization and the supplemental frame blending seem to mismatch. However, by leveraging their embeddedness in another field as well, interstitials can turn this mismatch around and reach surprisingly strong resonance within the focal field. Central condition for this strong resonance is that the discursive actions connect with another field that supports the framing which is argued for. An example from our data is the CDO and former entrepreneur Rachel Sterne who successfully argued that openness as an organizing principle needed to be imported from the realm of technology entrepreneurship, where it had already led to an outburst of innovation.

\section{Discussion}

Using the particularly revelatory case of the NYC administration, we studied how discursive tactics and social positions of actors affect the framing of innovation practices in interstitial issue fields. We found that actors equipped various social positions - insider, outsider, and interstitial - and two discursive tactics - reflective and supplemental frame blending - to frame open innovation practices as a viable alternative to the established innovation practice of the policy cycle. We further theorized these findings with a framework on enabling conditions for the cultural resonance of an innovation practice in an issue field. These insights contribute to several debates in innovation studies and the framing literature.

\section{Contributions to Innovation Studies}

Our study speaks to three ongoing discussions in innovation studies. First, we contribute to research on enabling conditions of public open innovation by showcasing how communicative actions at the field-level enable the use of open innovation practices. As our findings illustrate, 
the communicative actions of actors within city agencies (insiders), outside of them (outsiders), and actors from other fields now employed by city agencies (interstitials) framed open innovation practices to enhance the cultural resonance for public sector organizations. These findings make the case that discourses in issue fields are an important extra-organizational enabling condition of public open innovation, thereby adding to research on enabling conditions for public open innovation that so far focused on the level of the individual employee or the single public sector organization (Bekkers et al., 2013; Felin \& Zenger, 2014; Kankanhalli, Zuiderwijk, \& Tayi, 2017; Murray, et al., 2012). These insights can also be of great value for policy makers searching for enabling conditions for public open innovation that are complementary to formal open innovation strategies or budget allocation (Mergel, 2018).

Second, we contribute to research on public sector innovation (Arundel et al., 2015; Potts \& Kastelle, 2010; Sang et al. 2012). Specifically, we address the question if and how innovation practices that were pioneered in the private sector can be transposed to the public sector to address challenges of public service delivery in times of heterogeneous and turbulent environments (Bogers et al., 2018). Previous studies on open innovation in the public sector have either addressed the issue on conceptual grounds (Hilgers \& Ihl, 2010), assembled anecdotal evidence (Seltzer \& Mahmoudi, 2012), or examined differences between firms and public sector organizations with respect to the use of crowdsourcing as a specific open innovation practice (Mergel \& Desouza, 2013). With our study, we broaden the knowledge base with insights on different public open innovation practices (Dobusch \& Kapeller, forthcoming). With BigApps, we present an example of a competition aimed at open innovation through the provision of data generated by public organizations. With MODA, we showcase an example of an open innovation practice based on inter-agency collaboration. BetaNYC presents an example of how new practices of open innovation become possible when public sector organizations engage not only with a large and anonymous crowd, as is the case in studies on crowdsourcing in the public sector, but with a more specific community of engaged individuals.

Third, we add to the burgeoning research interested in how organizations leverage culture to innovate (Bartel \& Garud, 2009). Specifically, we address the question of how cultural resources are used to facilitate innovation practices across organizations. This question that the editors of this special issue have also raised reflects the key assumption of contemporary cultural research in organization studies that culture is constitutive for organizational practices and structures (Giorgi, et al., 2015; Weber \& Dacin, 2011). Taking a 
field framing perspective that specifies this assumption (Cornelissen \& Werner, 2014; Lounsbury et al., 2003) and embraces recent suggestions for using the framing lens to advance institutional theory (Purdy, et al., forthcoming), we focused on the use of cultural resource frames with respect to innovation practices. We found that framing changes the use of innovation practices and thus the way several organizations innovate. In our case, several organizations of the NYC administration increasingly used open innovation practices in addition to the established innovation practice of the policy cycle. With this finding, we add to extant research on the role of framing that has mainly been interested in how frames shape innovation outcomes but not how framing shapes how organizations innovate more broadly (Bartel \& Garud, 2009; Salomo et al., 2008; van Burg, Berends, \& van Raaij, 2014).

\section{Contributions to the Framing Literature}

Our findings further contribute to the framing literature in two ways. First, we contribute to research on how actors engage in frame blending. In their theoretical work, Werner and Cornelissen (2014, p. 1465) argued "that actors will use the same frames that they articulated to make sense of the change as a basis for their strategic persuasion of others." Our study provides empirical evidence for this argument. In NYC, actors used frames related to open innovation practices in the private domain to frame open innovation practices as valid alternative next to the established innovation practice in the public sector. In addition, we introduce an important variation in frame blending: the provenance of words and schemas used to blend a field frame. When engaging in reflective frame blending, actors advocate a frame change by leveraging frames that are part to the current field discourse. When engaging in supplemental frame blending, actors advocate a frame change by leveraging frames that are not part to the current field discourse. With this finding, we extend current theory by showing that frame blending varies not only with respect to the degree of change compared to prior frames, but also regarding the provenance of words and schemas (Werner \& Cornelissen, 2014).

Second, we contribute to the framing literature with a theoretical framework on the enabling conditions for the cultural resonance of an innovation practice in an issue field. This framework clarifies that the likelihood of a framing activity to enhance the cultural resonance of an innovation practice in an issue field varies with respect to two dimensions. The dominant discursive tactic that actors use - either reflective frame blending or supplemental frame blending - presents one dimension. The second dimension is the social position of the framing actor. While we are not the first to highlight the importance of an actor's social position in an issue field (Furnari, 2014, 2017; Maguire, et al. 2004), we provide a nuanced classification of 
distinct social positions (outsiders, insiders, interstitials) that allows us to clarify more accurately the likelihood of a framing activity to positively affect the cultural resonance of innovation practices. In sum, our framework suggests that whether the rhetoric of articulated field change - in our case the use of open innovation practices - finds resonance with targeted actors - in our case city agencies - or not, is contingent upon the variant of frame blending and the social position of actors engaged in frame blending. This framework presents a first step towards contingency-oriented theorizing of possible pathways for frame blending to change issue fields and especially adds to the theoretical work of Werner and Cornelissen (2014) and Furnari (2017) on change in issue fields. Our model builds on this work but provides a more actor-oriented view of frame blending that follows recent calls to put "multiply embedded actors" (Zietsma, 2017, p. 407) in interstitial issue fields center stage. As our framework shows, not only a field's stability and breadth of discursive opportunities (Werner \& Cornelissen, 2014) and the centralized or fragmented structure of an issue field (Furnari, 2017) are important conditions to understand field change, but also the position of actors in the field. In NYC, actors that are members of the city administration yet maintain ties to the field of technology entrepreneurship and business have a particularly high likelihood of success when trying to affect the dominant field frame through frame blending. The CDO Rachel Sterne presents a case in point.

\section{Limitations and Further Research}

Our study is not without limitations. A first limitation concerns the generalization of our theorizing. Our model was developed through abductive reasoning. While abductive reasoning allows scholars to infer enabling conditions by iterating between theory and observation, the selection of one explanation over another remains to some degree "presumptive and conjectural" (Mantere \& Ketokivi, 2013, p. 72). Thus, further empirical research is needed to test and enhance the robustness of our framework. A second limitation concerns the condition of the issue field. Issue fields related to public administrations such as the NYC administration can be considered as established fields, in which "field members know what to expect from each other, and within any given action domain within the field, there is a clear set of mutually reinforcing institutional arrangements that guide behavior" (Zietsma, 2017, p 403). Further research is needed to scrutinize how our findings hold true in less established fields in which innovation practices might emerge at a different pace and without the constant evaluation against established practices. A third limitation concerns our level of analysis. While the field level presents an important level to clarify fundamental enabling conditions that are not fully at 
the discretion of organizations, further research is needed to link field-level and organizational level enabling conditions for the use of innovation practices in the public sector (Mergel, 2018). A final limitation arises from our case sampling. Our case of the NYC administration presents an extreme case where actors engaged in framing activities did not compete antagonistically but held similar or at least compatible visions about the direction of change. Such broader common understanding cannot be assumed in any issue field on innovation. Consider, for example, the discourse about genetic engineering as an innovation practice in agricultural markets. These and other issue fields are contested (Meyer \& Höllerer, 2010) and seem to be more prone to framing contests where "the framing of one group is often rebutted or challenged by frames of other groups" (Werner \& Cornelissen, 2014, p. 1449). To develop more general theories on the cultural foundations of innovation, comparative studies that contrast our findings with those from more contested interstitial issue fields are needed.

\section{Conclusion}

Our study set out to provide a better understanding of the role of culture in how organizations innovate. While our empirical context is the public sector, we believe that our findings showcase more broadly how cultural templates enable innovation practices. Specifically, our findings provide a complementary perspective on more traditional perspectives that explain the form of innovation primarily with a focus on costs and benefits (West \& Bogers, 2017). As we have demonstrated, the use of open innovation practices is not only shaped by their costs and benefits, but also by their cultural resonance. Such emphasis on the role of culture for innovation is much needed. While cultural approaches have become a cornerstone in organization studies (Giorgi et al, 2015; Weber \& Dacin, 2011) and entrepreneurship research (Lounsbury \& Glynn, 2001), their application to foster our understanding of innovation is still scarce. We hope that our study is one of many steps to make cultural approaches a cornerstone in innovation studies as well.

\section{Acknowledgments}

We are indebted to the guest editor Stine Grodal and two anonymous reviewers for their exceptional feedback. We would further like to thank Guido Möllering, Leona Henry, and Clemens Wagner for valuable comments on previous versions of the manuscript. The empirical work of this research project was funded through a doctoral scholarship granted to the first author by the Foundation of German Industry. 


\section{Declaration of Interest Statement}

The authors report no potential conflict of interest.

\section{References}

Ansari, S.M., Fiss, P.C., \& Zajac, E.J. (2010). Made to fit: How practices vary as they diffuse. Academy of Management Review, 35(1), 67-92.

Arundel, A., Casali, L., \& Hollanders, H. (2015). How European public sector agencies innovate: The use of bottom-up, policy-dependent and knowledge-scanning innovation methods. Research Policy, 44(7), 1271-1282.

Bartel, C.A. \& Garud, R. (2009). The role of narratives in sustaining organizational innovation. Organization Science, 20(1), 107-117.

Bekkers, V. J. J. M., Tummers, L. G., \& Voorberg, W. H. (2013). From public innovation to social innovation in the public sector: A literature review of relevant drivers and barriers. Working Paper Erasmus University Rotterdam.

Bogers, M., Chesbrough, H., \& Moedas, C. (2018). Open innovation: Research, practices, and policies. California Management Review, 60(2): 5-16.

Chesbrough, H. (2003). Open innovation: The new imperative for creating and profiting from technology. Boston: Harvard Business School Press.

Cohen, B., Almirall, E., \& Chesbrough, H. (2016). The city as a lab: Open innovation meets the collaborative economy. California Management Review, 59(1), 5-13.

Corbin, J. M. \& Strauss, A. L. (1990). Basics of qualitative research: Techniques and procedures for developing grounded theory. Los Angeles: Sage.

Cornelissen, J. P. \& Werner, M. D. (2014). Putting framing in perspective. Academy of Management Annals, 8, 181-235.

De Vaan, M., Stark, D., \& Vedres, B. (2015). Game changer: The topology of creativity. American Journal of Sociology, 120(4), 1144-1194.

Dobusch, L. \& Kapeller, J. (forthcoming). Open strategy-making with crowds and communities: Comparing wikimedia and creative commons. Long Range Planning.

Eisenhardt, K. M. (1989). Building theories from case study research. Academy of Management Review, 14(4): 532-550.

Felin, T., \& Zenger, T. R. 2014. Closed or open innovation? Problem solving and the governance choice. Research Policy 43(5): 914-925.

Furnari, S. (2014). Interstitial spaces: Microinteraction settings and the genesis of new practices between institutional fields. Academy of Management Review, 39(4): 439-462.

Furnari, S. (2017). When does an issue trigger change in a field? A comparative approach to issue frames, field structures and types of field change. Human Relations, 71(3): 321-348.

Giorgi, S., Lockwood, C., \& Glynn, M.A. (2015). The many faces of culture: Making sense of 30 years of research on culture in organization studies. Academy of Management Annals, 9 , $1-54$

Goffman, E. (1974). Frame analysis: An essay on the organization of experience. New York: Harper \& Row.

Goldstein, B. \& Dynson, L. (2013). Beyond transparency: Open data and the future of civic innovation. San Francisco: Code for America Press.

Heimstädt, M. \& Reischauer, G. (2018). Open(ing up) for the future: Practising open strategy and open innovation to cope with uncertainty. In: H. Krämer \& M. Wenzel (Eds.), How organizations manage the future: Theoretical perspectives and empirical insights, Basingstoke: Palgrave Macmillan: 113-131. 
Hilgers, D. \& Ihl, C. (2010). Citizensourcing: Applying the concept of open innovation to the public sector. International Journal of Public Participation, 4(1), 67-88.

Kankanhalli, A., Zuiderwijk, A., \& Tayi, G.K. (2017). Open innovation in the public sector: A research agenda. Government Information Quarterly, 34(1), 84-89.

Lathrop, D. \& Ruma, L. (Eds.). (2010). Open government: Collaboration, transparency, and participation in practice. Sebastopol: O'Reilly Media.

Lounsbury, M. \& Glynn, M.A. (2001). Cultural entrepreneurship. Stories, legitimacy, and the acquisition of resources. Strategic Management Journal, 22(6-7), 545-564.

Lounsbury, M., Ventresca, M., \& Hirsch, P.M. (2003). Social movements, field frames and industry emergence: A cultural-political perspective on US recycling. Socio-Economic Review, 1(1), 71-104.

Maguire, S., Hardy, C., \& Lawrence, T. B. 2004. Institutional entrepreneurship in emerging fields: HIV/aids treatment advocacy in canada. Academy of Management Journal, 47(5): 657-679.

Meyer, R. E. \& Höllerer, M. A. 2010. Meaning structures in a contested issue field. A topographic map of shareholder value in austria. Academy of Management Journal, 53(6): 1241-1262.

Mantere, S. \& Ketokivi, M. (2013). Reasoning in organization science. Academy of Management Review, 38(1): 70-89.

Murray, F., S. Stern, G. Campbell, and A. MacCormack. 2012. Grand innovation prizes: A theoretical, normative, and empirical evaluation. Research Policy 41(10): 1779-1792.

Mergel, I. \& Desouza, K.C. (2013). Implementing open innovation in the public sector: The case of Challenge.gov. Public Administration Review, 73(6), 882-890.

Mergel, I. (2018). Open innovation in the public sector: Drivers and barriers for the adoption of challenge.gov. Public Management Review, 20(5), 726-745.

Phillips, N., Lawrence, T. B., \& Hardy, C. (2004). Discourse and institutions. Academy of Management Review, 29(4), 635-652.

Potts, J. \& Kastelle, T. (2010). Public sector innovation research: What's next? Innovation: Organization \& Management, 12(2): 122-137.

Purdy, J., Ansari, S., \& Gray, B. (forthcoming). Are logics enough? Framing as an alternative tool for understanding institutional meaning making. Journal of Management Inquiry.

Sang, M. L., Taewon, H., \& Donghyun, C. (2012). Open innovation in the public sector of leading countries. Management Decision, 50(1): 147-162.

Reischauer, G. (2018). Industry 4.0 as policy-driven discourse to institutionalize innovation systems in manufacturing. Technological Forecasting \& Social Change, 132: 26-33.

Salomo, S., Talke, K., \& Strecker, N. (2008). Innovation field orientation and its effect on innovativeness and firm performance. Journal of Product Innovation Management, 25(6), 560-576.

Seltzer, E. \& Mahmoudi, D. (2012). Citizen participation, open innovation, and crowdsourcing. Journal of Planning Literature, 28(1), 3-18.

van Burg, E., Berends, H., \& van Raaij, E.M. (2014). Framing and interorganizational knowledge transfer: A process study of collaborative innovation in the aircraft industry. Journal of Management Studies, 51(3), 349-378.

Vedres, B., \& Stark, D. (2010). Structural folds: Generative disruption in overlapping groups. American Journal of Sociology, 115(4), 1150-1190.

Weber, K. \& Dacin, M.T. (2011). The cultural construction of organizational life. Organization Science, 22(2), 287-298.

Weikart, L. A. (2001). The Giuliani administration and the new public management in New York City. Urban Affairs Review, 36(3): 359-381 
Werner, M.D. \& Cornelissen, J.P. (2014). Framing the change: Switching and blending frames and their role in instigating institutional change. Organization Studies, 35(10), 1449-1472.

West, J. \& Bogers, M. (2017). Open innovation: Current status and research opportunities. Innovation: Organization \& Management, 19(1), 43-50.

Yin, R. K. 2013. Case study research: Design and methods (5. ed.). Los Angeles: Sage.

Zietsma, C., Groenewegen, P., Logue, D., \& Hinings, C.R. (2017). Field or fields? Building the scaffolding for cumulation of research on institutional fields. Academy of Management Annals, 11, 391-450. 
Table 1

Data overview

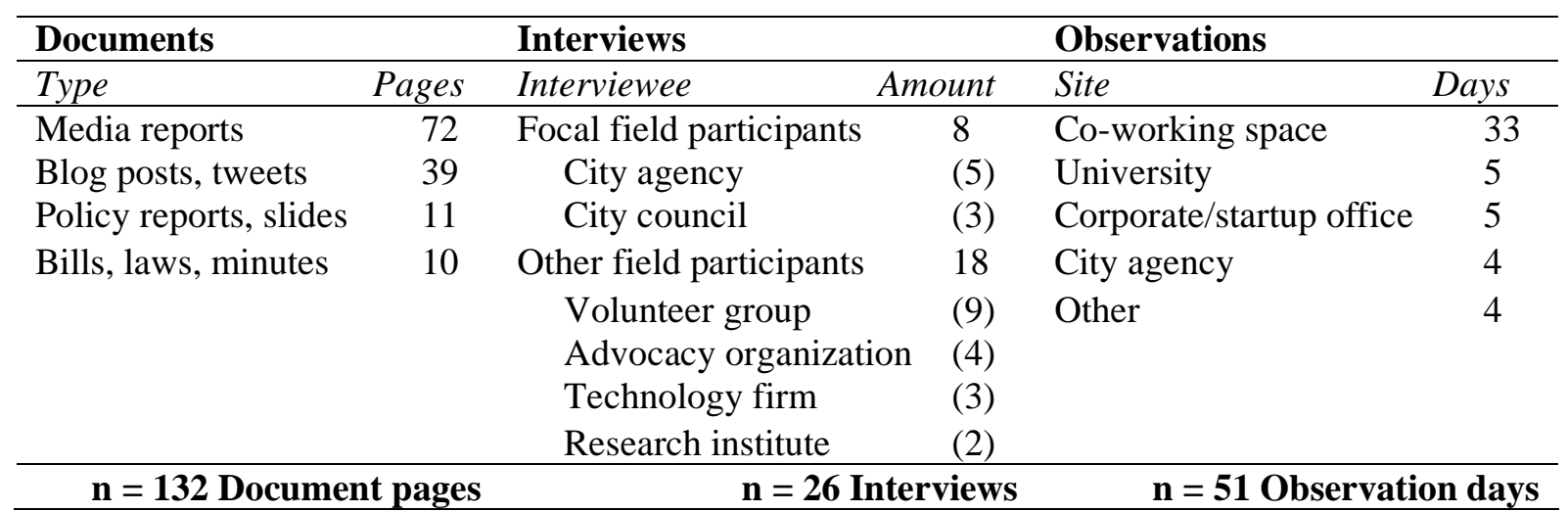


Table 2

Selected key events in observation phase

\begin{tabular}{ll}
\hline Year & \multicolumn{1}{c}{ Event } \\
\hline 2002 & Michael Bloomberg becomes 108 \\
2003 & $\begin{array}{l}\text { City administration established non-emergency hotline ("311") to make it easier for } \\
\text { citizens to get information on public services }\end{array}$ \\
2008 & $\begin{array}{l}\text { First meeting of the civic technology volunteer group BetaNYC } \\
\text { City administration launches web portal with data sets from various agencies }\end{array}$ \\
2009 & $\begin{array}{l}\text { First city-sponsored app developer competition "BigApps" takes place } \\
\text { Mayor's Office for Data Analytics (MODA) is established }\end{array}$ \\
& $\begin{array}{l}\text { City government names city's first Director of Analytics to head MODA } \\
\text { City government creates role of Chief Digital Officer }\end{array}$ \\
2011 & $\begin{array}{l}\text { MODA launches the platform DataBridge to facilitate data sharing and cooperation } \\
\text { on innovation problems between city agencies }\end{array}$ \\
2014 & $\begin{array}{l}\text { Bill de Blasio becomes 109 } \\
\text { Mayor Mayor of NYC Blasio appoints new Director of Analytics and head of MODA } \\
\text { BetaNYC becomes official partner of Manhattan Borough President's office to } \\
\text { develop a training program on citizen innovation using public sector data }\end{array}$ \\
&
\end{tabular}


Table 3

Forms of frame blending and exemplary data

\begin{tabular}{|c|c|}
\hline Type and definition & Exemplary data \\
\hline \multirow{2}{*}{$\begin{array}{l}\text { Reflective } \\
\text { frame blending }\end{array}$} & $\begin{array}{l}\text { Outsider: In a media op-ed, a public policy professor made the case that when city agencies share their information } \\
\text { with the central innovation hub MODA, they do not engage in an entirely new practice, but a "leveraged", and "more } \\
\text { sophisticated" way of "comprehend[ing] the metabolism of the city [...]." (Governing.com, September 16, 2015) }\end{array}$ \\
\hline & $\begin{array}{l}\text { Insider: A high-ranking city manager praised city agencies who have voluntarily contributed data sets to the BigApps } \\
\text { competition and thereby signaled to other agencies that "the sky didn't fall" (Politico, March } 21,2012) \text {. The city manager } \\
\text { stressed that the public service innovations that resulted from the competition are something that city agencies can foster } \\
\text { by taking a "leap of faith". (Personal interview) }\end{array}$ \\
\hline $\begin{array}{l}\text { Recombining and revisiting } \\
\text { words and schemas that are } \\
\text { already part of the field } \\
\text { discourse. }\end{array}$ & $\begin{array}{l}\text { Interstitial: Mayor Bloomberg emphasized that the information to be released for the first BigApps competition already } \\
\text { belongs to the public, but that this relationship just needed to be renewed: "The information we're providing is the } \\
\text { public's, and we're relying on the creativity and talent of New York City's tech and entrepreneurial communities to come } \\
\text { up with innovative and helpful ways to use it." (Press release, October 6, 2009) }\end{array}$ \\
\hline \multirow{2}{*}{$\begin{array}{l}\text { Supplemental } \\
\text { frame blending }\end{array}$} & $\begin{array}{l}\text { Outsider: A corporate evangelist explains his role in the local government field in NYC: "Our team focuses on cities } \\
{[\ldots] \text { that have Mayors trying to innovate and a whole community of [civic hacking] groups that are helping to innovate. }} \\
\text { It's not just the IT department anymore deciding on technology, it's the whole community of people inside and outside of } \\
\text { government building this technology. [...] We don't go and lobby the government or anything. We just get to hang out } \\
\text { with them at a hackathon." (Personal interview) }\end{array}$ \\
\hline & $\begin{array}{l}\text { Insider: In our interview, a senior city employee recalls how he internally framed the need to contribute data sets to the } \\
\text { BigApps developer competition: [Opening data] was something that [Washington] D.C. is doing. I said: 'If we want to } \\
\text { keep New York ahead of the curve, we should think about this, too'." (Personal interview) }\end{array}$ \\
\hline $\begin{array}{l}\text { Bringing in and leveraging } \\
\text { words and schemas that have } \\
\text { not yet been part of the field } \\
\text { discourse. }\end{array}$ & $\begin{array}{l}\text { Interstitial: The NYC Director of Analytics, Mike Flowers, makes the argument that problem-solving techniques used } \\
\text { by US troops in Iraq can be transferred to public service problems in NYC. Agencies therefore need to share their data } \\
\text { more openly: "I tried to replicate what I saw in Baghdad here. [...] I saw generally what they were doing at a higher level } \\
\text { and thought, 'You can change that [algorithm from] finding bombs to finding bad guys [referring to issues of financial } \\
\text { crime in NYC], if only the data was there." Flowers also used this narrative in public appearances and media coverage to } \\
\text { promote MODA amongst city agencies. (Personal interview; media reports) }\end{array}$ \\
\hline
\end{tabular}


Figure 1

Enabling Conditions for the Cultural Resonance of Innovation Practices

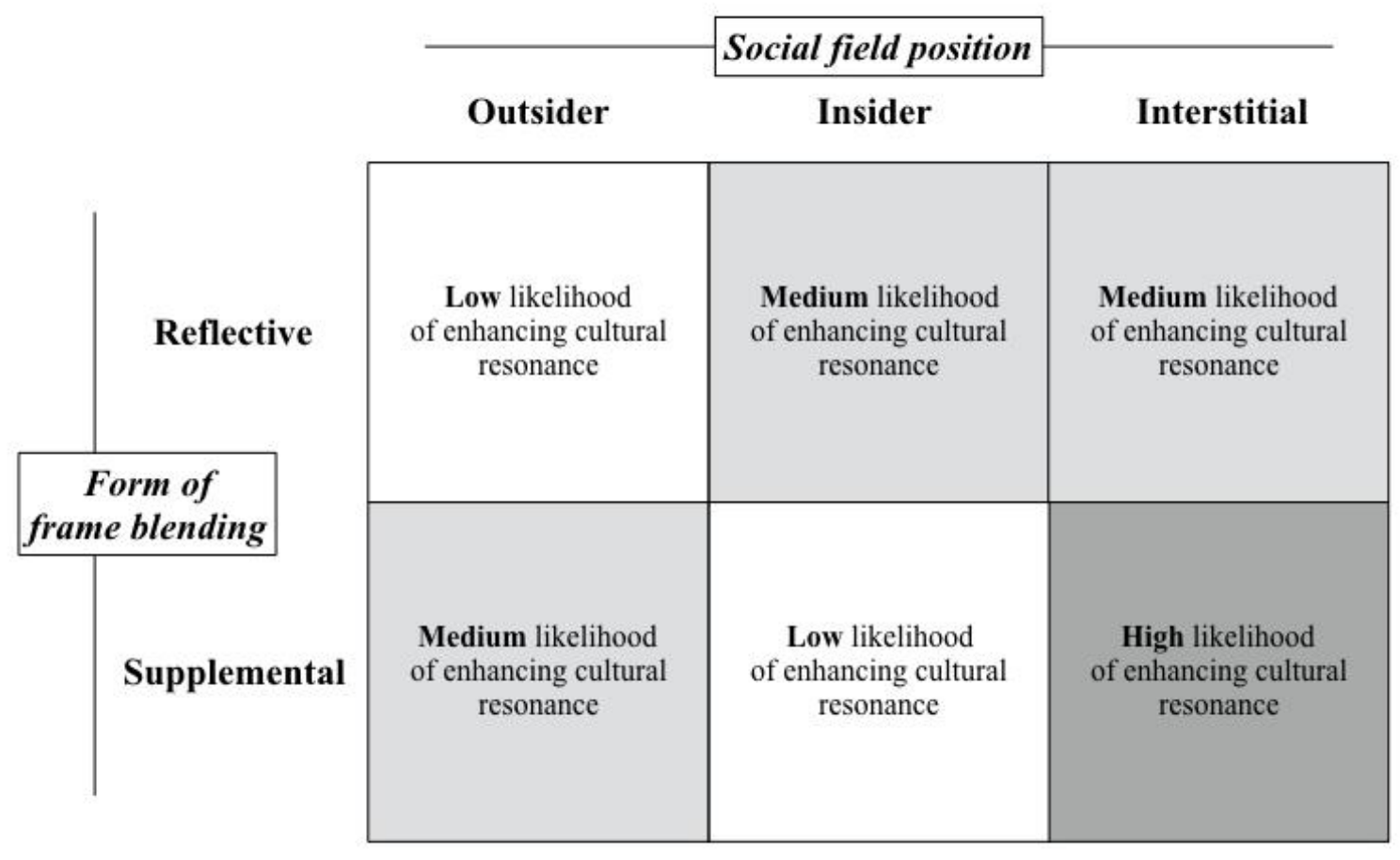

